\title{
Nutritional Status, Oxidant/Antioxidant and Inflammatory Markers in Scholar Athletes Adolescents
}

\author{
Assia Bouchouicha, Hanane Ghomari-Boukhatem, Malika Bouchenak* \\ Laboratoire de Nutrition Clinique et Métabolique. Faculté des Sciences de la Nature et de la Vie, Université d’Oran1 Ahmed Ben Bella, \\ BP 1524 El M’Naouer, 31000 Oran, Algeria \\ *Corresponding author: bouchenak.malika@lncm-univoran.com
}

\begin{abstract}
In the last two or three decades, physical activity (PA) has gained increasing recognition as being essential for maintaining good health and improving quality of life for all ages. To evaluate the nutritional status, oxidant/antioxidant, and inflammatory markers, in sports adolescents, a cross sectional study has done in west Algeria. A total of 110 athletes adolescents from special sport classes, aged 11-17 years, were compared to a non athletes group $(n=60)$. Blood pressure, anthropometric and serum parameters were measured. Daily energy intake (DEI) was estimated using 24 hours recall, followed by a 3-days record. Energy expenditure (EE) was evaluated by the International Physical Activity Questionnaire-short form (IPAQ-S). Oxidant/antioxidant and inflammatory markers were determined. An increase in body weight and height $(p<0.001)$ was noted in athletes compared to non athletes. DEI was similar in both groups, whereas EE was higher in athletes than non athletes $(p<0.001)$. Serum triacylglycerol (TG) values were lower in athletes group than in non athletes $(p<0.05)$. Enhanced values were observed in glutathione peroxidase (GPx) $(p<0.001)$, and superoxide dismutase (SOD) $(p<0.05)$ activity, and tumor necrosis factor- $\alpha(\mathrm{TNF}-\alpha)(p<0.01)$ in athletes compared to non athletes. Significant relationships were found between height, weight, albumin, GPx, TNF- $\alpha$, IL-1, and EE. Significant associations were noted between GPx $(\mathrm{OR}=0.14 ; 95 \% \mathrm{CI} 0.03,1.05)$, inflammatory markers TNF- $\alpha(\mathrm{OR}=0.47 ; 95 \%$ CI 0.28, 0.80), IL-1 (OR=1.17; 95\% CI $0.28,0.80)$ and physical activity. Significant relationships were found between weight $(P<0.001)$, height $(P<0.01)$, albumin, GPx, IL-1, TNF $\alpha(P<0.05)$ and EE. In spite of inadequate DEI in athletes adolescents, beneficial effect of sport is observed by lowering serum TG concentrations. However, more research in this area is warranted to clarify sport nutrition needs to provide better and healthy nutritional guidance to young athletes.
\end{abstract}

Keywords: athlete adolescent, energy expenditure, daily energy intake, oxidant/antioxidant status, inflammatory markers

Cite This Article: Assia Bouchouicha, Hanane Ghomari-Boukhatem, and Malika Bouchenak, "Nutritional Status, Oxidant/Antioxidant and Inflammatory Markers in Scholar Athletes Adolescents." American Journal of Sports Science and Medicine, vol. 5, no. 4 (2017): 75-81. doi: 10.12691/ajssm-5-4-3.

\section{Introduction}

In order to improve health, World Health Organization recommends that adolescents should accumulate, at least, 60 minutes of daily physical activity (PA), that is of moderate - to vigorous - intensity [1]. This includes activities such as brisk walking, bicycling, and soccer [2]. Childhood and adolescence represent a period of rapid growth and development. Both are influenced by nutrition and PA, which therefore play a particularly important role during this phase of life [3]. Appropriate nutrition during this period is a basic requirement to express genetic potential that, together with PA, will influence later adult and elderly health outcomes [4]. The protective role of PA on cardiometabolic risk, in children and adolescents, has been described in the literature. Indeed, studies have demonstrated that vigorous PA ameliorates levels of total cholesterol (TC), triglycerides (TG), and blood pressure (BP), and decreases waist circumference (WC) in this population [5]. Nutrition is an important part of sport performance for young athletes, in addition to allowing for optimal growth and development, macronutrients, micronutrients and fluids, in the proper amounts, are essential to provide energy for growth and activity [6].

Furthermore, good nutritional practices are important for exercise performance, and health during all ages. Athletes, and especially growing children, engaged in heavy training, have higher energy and nutrient requirements, compared to their non-active counterparts. Most of the sports nutrition recommendations given to athletic children and adolescents are based on adult findings due to the deficiency in age specific information in young athletes [7]. During sports training, athletes are continuously exposed to various kind of stress [8]. However, it has been reported that acute aerobic exercise induces oxidative stress (OS), whereas regular aerobic exercise decreases oxidant markers, and increases anti-oxidant enzyme activities [9].

PA and fitness may be important protective factors for low-grade inflammation [10]. Therefore, evidence is scarce and results are mixed regarding the association of PA and fitness with inflammation in adolescents. In 
addition, previous studies on inflammation in this age group had some critical methodological limitations [11].

Therefore, the objective of this study was to evaluate the nutritional status, oxidant/antioxidant, and inflammatory markers, in athletes compared to non athletes adolescents.

\section{Methods}

\subsection{Study Design}

A cross sectional study was done on adolescents, aged 11-17 years, recruited between March 2011 and May 2012, in Oran city (West Algeria) college, from $1^{\text {st }}$ to $4^{\text {th }}$ secondary classes. An athlete group was composed of 110 adolescents (sex ratio $\mathrm{G} / \mathrm{B}=28 / 82$ ), from special sport classes, practicing in average 7 hours of sport per week in school (60\% handball and $40 \%$ athletic sport), and $50 \%$ of them practiced between 2 and 9h/week of sport after school (football, swimming, judo, kick-boxing, athletic sport, tennis). This group was compared to non athletes which were composed of 60 students (sex ratio $\mathrm{G} / \mathrm{B}=$ 27/33), practicing 2 hours of sport per week in school. All adolescents were healthy, using no medications or supplements, and were no-smokers.

The characteristics of the adolescents are shown in Table 1.

Table 1. Characteristics and family SES of adolescents

\begin{tabular}{|l|c|c|}
\hline Gender (Girls/Boys) & $\begin{array}{c}\text { Athletes } \\
(\mathrm{n}=110)\end{array}$ & $\begin{array}{c}\text { Non athletes } \\
(\mathrm{n}=60)\end{array}$ \\
Age (years) & $28 / 82$ & $27 / 33$ \\
\hline Weight $(\mathrm{kg})$ & $13 \pm 2$ & $13 \pm 1$ \\
\hline Height $(\mathrm{m})$ & $1.56 \pm 0.12^{* * *}$ & $1.50 \pm 0.08$ \\
\hline BMI $\left(\mathrm{kg} / \mathrm{m}^{2}\right)$ & $18.63 \pm 3.18$ & $17.85 \pm 3.17$ \\
\hline Pubertal status I/II/III/IV/V (\%) & $2 / 18 / 41 / 31 / 8$ & $3 / 21 / 38 / 28 / 10$ \\
\hline Family SES (\%) & & \\
Low & 14.41 & 12.72 \\
Intermediate & 69.36 & 74.54 \\
High & 16.21 & 12.72 \\
\hline Waist circumference (cm) & $75.47 \pm 11.89$ & $76.65 \pm 8.07$ \\
\hline Systolic BP (mmHg) & $105.0 \pm 8.1$ & $110.5 \pm 10.5$ \\
\hline Diastolic BP (mmHg) & $55.0 \pm 5.1$ & $58.0 \pm 6.1$ \\
\hline Glucose (mmol/L) & $5.00 \pm 0.85$ & $5.16 \pm 0.92$ \\
\hline Cholesterol (mmol/L) & $4.03 \pm 0.86$ & $4.05 \pm 0.70$ \\
\hline Triacylglycerols (mmol/L) & $1.12 \pm 0.27^{*}$ & $1.27 \pm 0.30$ \\
\hline Urea (mmol/L) & $4.86 \pm 0.99$ & $4.70 \pm 1.01$ \\
\hline Total proteins (mmol/L) & $0.12 \pm 0.02$ & $0.13 \pm 0.02$ \\
\hline Hemoglobin (mmol/L) & $0.39 \pm 0.07$ & $0.36 \pm 0.08$ \\
\hline
\end{tabular}

Values are means \pm SD, SES: socio-economic status; BP: blood pressure; Low SES: children of mothers with a low educational level; Intermediate SES: children of mothers with an intermediate educational level; High SES: children of mothers with a high educational level. Differences were determined by the Student ' $\mathrm{t}$ ' test. ${ }^{*} p<0.05,{ }^{* *} p<0.01$ and ${ }^{* * *} p<0.001$.

\subsection{Ethic Statement}

The Ethic approval was obtained from the Committee of the Thematic Agency on Health Sciences Research, after receiving the institutional approval from the both Directories of Health and Education. An informed written consent was obtained from the parents or tutors, and verbal consent was provided by each adolescent.

\subsection{Anthropometric and Blood Pressure (BP) Measurements}

Anthropometric parameters were measured at school by trained operators, using standard equipments. Waist circumference (WC) was measured to the nearest $0.1 \mathrm{~cm}$ in standing position at the midpoint between the lowest rib and the iliac crest and at the end of normal expiration, using a measuring tape. Body weight (BW) was measured to the nearest $0.1 \mathrm{~kg}$ using portable scale (Seca, Germany), with minimal clothing and no shoes. Height was measured to the nearest $0.1 \mathrm{~cm}$ using a height bar (2 meters, dismantling) without shoes. Body mass index (BMI) was calculated as weight in kilogram divided by the square of height in meter $\left(\mathrm{kg} / \mathrm{m}^{2}\right)$.

$\mathrm{BP}$ was measured in a sitting position, after $10 \mathrm{~min}$ rest period. The averages of two systolic (SBP) and diastolic blood pressure (DBP) measures were recorded at $5 \mathrm{~min}$ intervals.

\subsection{Socioeconomic Status (SES)}

In the present study, we used maternal educational level as an indicator of SES, as it is one of the three commonest indicators of SES and has been found to be the strongest and most consistent SES indicator for predicting healthrelated behavior [12]. Maternal educational level was classified into three groups: 'low educational level' (primary school and lower secondary education); 'intermediate educational level' (intermediate vocational level, higher secondary school); 'high educational level' (higher vocational education and university). In the remainder of this article, we refer to these groups as 'low SES' (children of mothers with a low educational level), 'intermediate SES' (children of mothers with an intermediate educational level) and 'high SES' (children of mothers with a high educational level).

\subsection{Energy Expenditure}

The physical activity was measured using a French version of the International Physical Activity Questionnaire-short form (IPAQ-S) [13]. The IPAQ-S asks students to selfrecall different types of activities (moderate, vigorous) they performed during the past 7 days. The students were provided with descriptions and examples of each activity types and were asked to record the number of days and the lasting time (in minutes) for each day of the types of activity they participated. Each day's moderate or vigorous PA time was added up. The total weekly MVPA time was calculated by the weekly sum of both moderate and vigorous PA time. The reliability and validity of IPAQ-S across 12 countries have been established before [13].

The physical activity questionnaire collects complete information on frequency, duration and intensity of light-moderate- and vigorous-intensity physical activities during a typical week and includes domains such as transport, household, fitness and sports activities.

Moderate-intensity activities were assigned MET (metabolic equivalent of task) values based on the compendium of physical activities [14], and the compendium of physical activities for youth [2]. 
Moderate-intensity recreational sports were assigned an average MET value equivalent to $4 \mathrm{MET}$. Slow walking, normal-pace walking and brisk walking were assigned MET values of $2 \cdot 8,3.5$ and $4.5 \mathrm{MET}$, respectively, based on modified MET values from the compendium for youth [2]. Vigorous-intensity physical activity and sports included jogging, running, bicycling, self defense, athletic sport, basket ball, handball and singles tennis. Such sports were assigned an average value of $8 \mathrm{MET}$.

\subsection{Daily Energy Intake}

Food consumption was estimated using 24 hours recall, followed by a 3-days record. Adolescents were interviewed by trained interviewers, using an adapted and structured questionnaire. Each subject was asked to recall everything they had eaten or drunk during the 24 hours preceding the interview. The day was chronologically organized into breakfast, collation, lunch, snack, and dinner. The meals were structured by entry, principal dish accompaniments, bread, and drinks. The interview was organized with specific questions about ingredients, and methods of preparation. Serving sizes were estimated by the use of food portion model handbook. The 3-days record was completed by the adolescents. The quantitative assessment of nutrient foods (daily energy intake (DEI), proteins, fats, carbohydrates, vitamins and minerals) was achieved by GENI software [15].

\subsection{Blood Sampling}

Blood samples were collected after 12 hours fasting from antecubital venipuncture, between 8:00 and 9:00 am. Serum was collected by low speed centrifugation at $3000 \times g$ at $4^{\circ} \mathrm{C}$, for $15 \mathrm{~min}$. The samples were separated in aliquots and frozen immediately at $-75^{\circ} \mathrm{C}$ until determination could be performed.

\subsection{Assays}

Glucose, uric acid, urea, TC and albumin were measured by enzymatic colorimetric methods (kits Spinreact, Spain). Triacylglycerols, hemoglobin, and total proteins were determined by enzymatic colorimetric methods (kits Chronolab, Spain).

Serum lipid peroxidation was estimated by measuring thiobarbituric acid reactive substances (TBARS) according to the method of [16]. The colored complex formed between malondialdehyde (MDA) and thiobarbituric acid (TBA) had maximum absorbance at $532 \mathrm{~nm}$. Superoxide dismutase (SOD) activity was measured by nicotinamide adenine dinucleotide (NADH) oxydation procedure (Fluka/Sigma-Aldrich, Buchs, Switzeland). Briefly, the method uses xanthine and xanthine oxydase to generate superoxide radicals, which react with 2-(4-iodophenyl)-3(4-netrophenyl)-5-phenyltetrazoluim chloride to form a formazan dye. The SOD activity was measured by the inhibition degree of the reaction at 440nm. Glutathione peroxidase (GPx), and glutathione reductase (GRed) activities were determined by using assay kits (Sigma, Missouri, USA). GPx activity was measured indirectly through a couple with glutathione reductase. Oxidized glutathione produced upon reduction of an organic hydroperoxide by GPx was recycled to its reduced state by GSH-Red and nicotinamide adenine dinucleotide phosphate (NADPH). The oxidation of NADPH to oxidized forms (NADP+) was accompanied by a decrease in absorbance at $340 \mathrm{~nm}$. One unit of enzyme was defined as $1 \mu \mathrm{mol}$ of $\mathrm{NADPH}$ oxidized/mg protein/min. GRed activity was determined by either the decrease in absorbance caused by the oxidation of NADPH at $340 \mathrm{~nm}$.

TNF- $\alpha$, and interleukin-1 (IL-1) were assayed in duplicate samples by commercial enzyme-linked immunosorbent assay kits (ELISA) (Cayman Chemical's ACE ${ }^{\mathrm{TM}}$ EIA kit, USA) with a range of $0-250 \mathrm{pg} / \mathrm{ml}$. The lower limit of detection was $3.9 \mathrm{pg} / \mathrm{ml}$ for TNF- $\alpha$ and IL-1. C-reactive protein (CRP) value was measured in duplicate samples with an immunometric assay kit (ELISA) (Cayman Chemical's ACE $^{\mathrm{TM}}$ EIA kit, USA) with a range of $0-3000 \mathrm{pg} / \mathrm{mL}$ and with a limit of detection of approximately $50 \mathrm{pg} / \mathrm{mL}$.

\subsection{Statistical Analysis}

Statistical analysis of the data was performed using IBM SPSS statistics version 20. Values were expressed as means \pm SD and percentages. The Shapiro-Wilk test was used to verify whether variable distribution was normal. The Student $t$-test was used to compare different variables in athletes group with those of non athletes. Correlations between energy expenditure and different variables were calculated using Pearson's coefficient. The Odds Ratio (OR) was estimated for each factor separately to evaluate its influence on PA. A $p$-value $=0.05$ was considered statistically significant with the confidence interval (CI) $95 \%$. OR was estimated using logistic regression analysis.

\section{Results}

\subsection{Anthropometric and Metabolic Characteristics}

There was no significant difference according to age and gender, between athletes and non athletes groups. However, body weight was 1.13-fold higher in athletes group $(46.36 \pm 12.79 \mathrm{~kg})$, than in non athletes $(40.74 \pm 10.79$ kg) $(p<0.01)$. Height was 1.05 -fold higher in athletes $(1.56 \pm 0.12 \mathrm{~m})$ than in non athletes $(1.50 \pm 0.08 \mathrm{~m})$ $(p<0.001)$. Nevertheless, there was no significant difference in BMI, and WC between the both groups. SBP and DBP values were similar in all adolescents. Moreover, serum concentrations of glucose, TC, urea, total proteins, and hemoglobin were similar in both groups, excepted serum TG values which were lower in athletes group $(1.12 \pm 0.27 \mathrm{mmol} / \mathrm{L})$ than in non athletes group $(1.27 \pm 0.30$ $\mathrm{mmol} / \mathrm{L})(p<0.05)$ (Table 1$)$.

\subsection{Socioeconomic Status}

Analysis of family socioeconomic status according to maternal educational level, showed that low SES was noted in $14 \%$ and $12 \%$ of athletes and non athletes groups, respectively. Intermediate SES was observed in 69\% and $74 \%$ of athletes and non athletes adolescents, respectively, and high SES in $16 \%$ and $12 \%$ of athletes and non athletes groups (Table 1). 


\subsection{Lifestyle of Adolescents}

The adolescent lifestyle (Table 2) showed that $28 \%$ of athletes, and $52 \%$ of non athletes groups spent $\geq 2 \mathrm{~h} /$ day watching television. The sleep duration was similar in the both groups. The time of sport in school was 2.82-fold higher in athletes than in non athletes adolescents. The daily breakfast consumption was noted in $74 \%$ and $71 \%$ of athletes and non athletes groups, respectively. The sugary drinks intake was $12 \%$ high in non athletes adolescents, compared to athletes group. Moreover, 46\% of athletes consumed fast-foods compared to $74 \%$ of non athletes adolescents. Nibbling was noted in 41\% and 33\% of athletes and non athletes groups, respectively.

Table 2. Daily Food Intake (DEI), Energy Expenditure (EE) and life style of athletes compared to non athletes

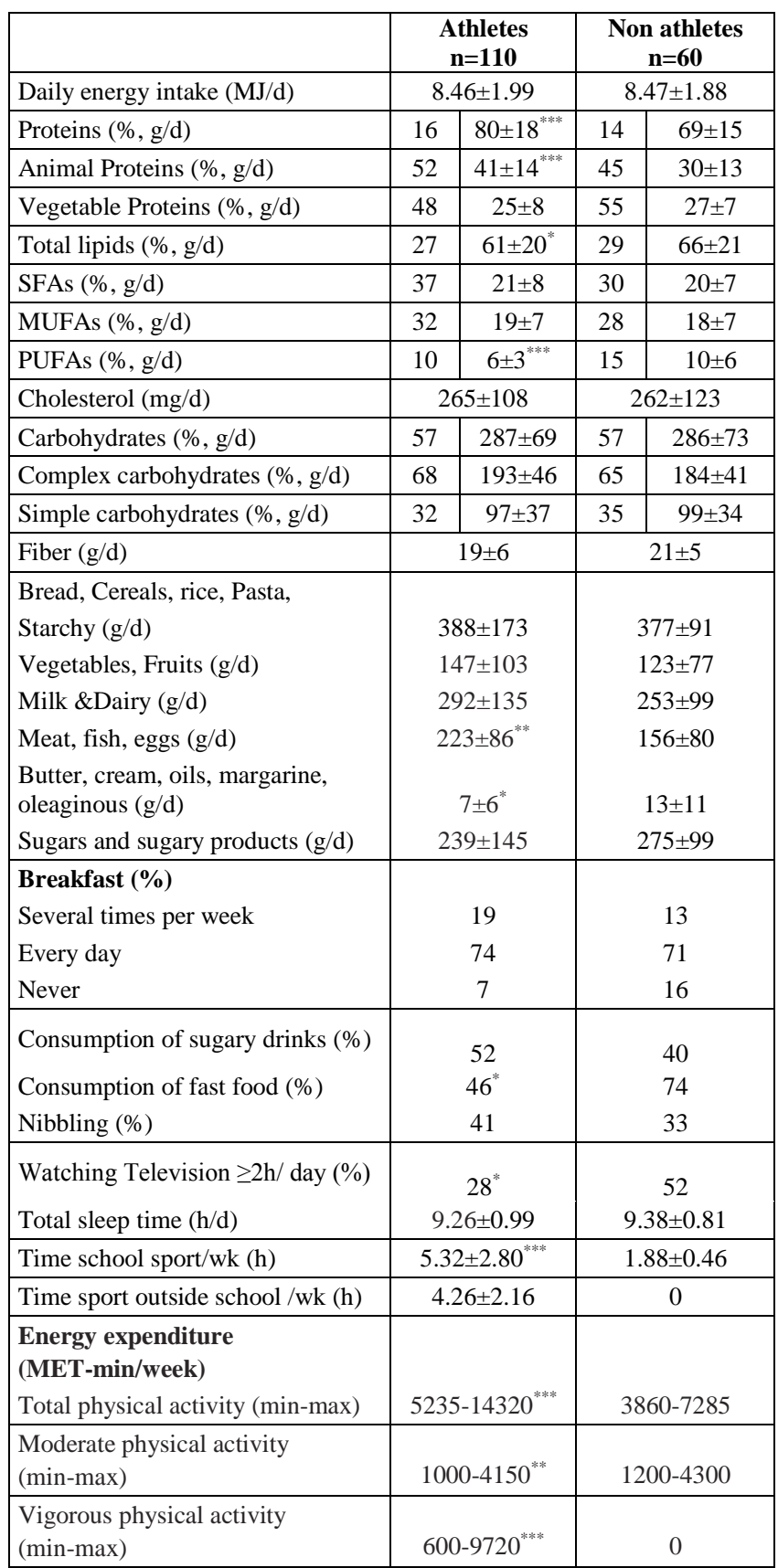

Values are means \pm SD, SFAs: Saturated fatty acids; MUFAs: Monounsaturated fatty acids; PUFAs: polyunsaturated fatty acids, MET: metabolic equivalent of task. Differences were determined by Student ' $\mathrm{t}$ ' test, ${ }^{*} p<0.05 ;{ }^{* *} p<0.01 ;{ }^{* * *} p<0.001$.

\subsection{Daily Energy Intake and Energy Expenditure}

The DEI of the adolescents, presented in Table 2, showed no significant difference in the both athletes and non athletes groups, and the values were respectively, $8.46 \pm 1.99$ and $8.47 \pm 1.88 \mathrm{MJ} /$ day. Qualitatively, total protein intake, and animal proteins were elevated in athletes compared to non athletes ( $80 \pm 18$ and $41 \pm 14 \mathrm{~g} /$ day vs $69 \pm 15$ and $30 \pm 13 \mathrm{~g} /$ day) $(p<0.001)$.

Carbohydrates consumption was similar in both groups, whereas, lower intake was noted in total lipids $(p<0.05)$, and in polyunsaturated fatty acids $(p<0.001)$, in athletes compared to non athletes group. Moreover, there was no significant difference in cholesterol, and fibers feeding between both groups. More consumption of meat/fish/eggs ( $p<0.01$ ), and less feeding butter, cream, oils, margarine, and oleaginous were observed in athletes adolescents compared to non athletes group.

Physical activity patterns and intensity differed between the both groups. As anticipated, athletes adolescents were more active than non athletes across a typical week and engaged in more vigorous-intensity physical activity than non athletes adolescents, who spent more time in moderate intensity physical activity.

\subsection{Oxidative Stress and Inflammatory Markers}

Lipid peroxidation, determined by TBARS concentrations, was similar in both athletes and non athletes groups (Table 3). Moreover, there was no significant difference in GRed, albumin and uric acid, whereas, in athletes adolescents, GPx and SOD activities were 1.32-fold and 1.09-fold higher than in non athletes group.

The inflammatory biomarkers (Table 3) showed that TNF- $\alpha$ value was 1.20 -fold higher in athletes than non athletes adolescents $(p<0.01)$. Nevertheless, CRP and IL-1 concentrations were similar between the both groups.

Table 3. Redox and inflammatory status of athletes adolescents compared to non athletes

\begin{tabular}{|l|c|c|}
\hline & $\begin{array}{c}\text { Athletes } \\
(\mathbf{n}=\mathbf{1 1 0})\end{array}$ & $\begin{array}{c}\text { Non athletes } \\
(\mathbf{n}=\mathbf{6 0})\end{array}$ \\
\hline TBARS (nmol/L) & $7.08 \pm 0.95$ & $6.93 \pm 0.85$ \\
\hline GPx (U/g Hb) & $2.18 \pm 0.73^{* * *}$ & $1.65 \pm 0.38$ \\
\hline GRed (U/g Hb) & $5.20 \pm 1.80$ & $5.70 \pm 1.80$ \\
\hline SOD (U/g Hb) & $8.99 \pm 1.43^{*}$ & $8.21 \pm 0.89$ \\
\hline Albumin (mmol/L) & $0.67 \pm 0.13$ & $0.65 \pm 0.96$ \\
\hline Uric acid ( $\mu \mathrm{mol} / \mathrm{L})$ & $0.18 \pm 0.56$ & $0.17 \pm 0.63$ \\
\hline CRP $(\mathrm{ng} / \mathrm{mL})$ & $0.30 \pm 0.05$ & $0.32 \pm 0.08$ \\
\hline TNF- $\alpha(\mathrm{pg} / \mathrm{mL})$ & $4.36 \pm 0.92^{* *}$ & $3.61 \pm 0.92$ \\
\hline IL1 (pg/mL) & $13.85 \pm 3.54$ & $13.87 \pm 3.22$ \\
\hline
\end{tabular}

Values are means \pm SD. TBARS: Thiobarbituric acid reactive substances; GPx: Glutathion peroxidase; GRed: Glutathion reductase; SOD: Superoxide dismutase; CRP: C-reactive protein; TNF $\alpha$ : Tumor necrosis factor $\alpha$; IL-1: Interleukin 1 . Differences were determined by Student ' $t$ ' test, ${ }^{*} p<0.05 ;{ }^{* *} p<0.01 ; * * * p<0.001$. 
Table 4. Correlations between variables and energy expenditure

\begin{tabular}{|l|c|c|}
\hline Variables & $R$ & $P$ \\
\hline Height & 0.280 & $<0.001$ \\
\hline Weight & 0.219 & $<0.01$ \\
\hline BMI & 0.177 & 0.068 \\
\hline Waist circumference & 0.054 & NS \\
\hline Glucose & 0.298 & NS \\
\hline Cholesterol & 0.096 & NS \\
\hline Triacylglycerols & 0.035 & NS \\
\hline Urea & -0.101 & NS \\
\hline Uric acid & 0.325 & NS \\
\hline Total proteins & 0.069 & NS \\
\hline Hemoglobin & 0.007 & NS \\
\hline DEI & 0.229 & NS \\
\hline Proteins & -0.171 & NS \\
\hline Animal proteins & 0.163 & NS \\
\hline Vegetable Proteins & 0.169 & NS \\
\hline Lipids & 0.213 & NS \\
\hline Carbohydrates & 0.132 & NS \\
\hline Simple carbohydrates & 0.114 & NS \\
\hline Complex carbohydrates & 0.157 & NS \\
\hline TBARS & -0.024 & NS \\
\hline Albumin & 0.459 & $<0.05$ \\
\hline GPx & 0.411 & $<0.05$ \\
\hline GRed & 0.223 & NS \\
\hline SOD & -0.263 & NS \\
\hline IL-1 & 0.381 & $<0.05$ \\
\hline CRP & 0.065 & NS \\
\hline TNF- $\alpha$ & 0.436 & $<0.05$ \\
\hline
\end{tabular}

BMI: body mass index, DEI: daily energy intake, TBARS: Thiobarbituric acid reactive substances, GPx: Glutathion peroxidase; GRed: Glutathion reductase; SOD: Superoxide dismutase; CRP: C-reactive protein; TNF $\alpha$ : Tumor necrosis factor $\alpha$; IL-1: Interleukin 1. NS: not statically significant.

Table 5. Multiple logistic regression analysis: association between energy expenditure and variables

\begin{tabular}{|l|c|c|c|}
\hline & OR & $95 \%$ CI & $P$ \\
\hline Gender & 0.37 & $0.13-1.05$ & 0.062 \\
\hline Pubertal status & 0.88 & $0.61-1.28$ & NS \\
\hline Waist circumference & 1.01 & $0.98-1.05$ & NS \\
\hline BMI & 1.05 & $0.95-1.15$ & NS \\
\hline Glucose & 1.37 & $0.78-2.38$ & NS \\
\hline Total cholesterol & 1.01 & $0.56-1.94$ & NS \\
\hline Triacylglycerols & 3.40 & $0.62-8.66$ & 0.12 \\
\hline Urea & 0.78 & $0.53-1.15$ & NS \\
\hline Uric acid & 1.00 & $0.99-1.00$ & NS \\
\hline Hemoglobin & 0.99 & $0.98-1.00$ & 0.13 \\
\hline Total proteins & 1.01 & $0.99-1.04$ & 0.16 \\
\hline GPx & 0.14 & $0.03-0.52$ & 0.004 \\
\hline GRed & 1.11 & $0.86-1.43$ & NS \\
\hline Albumin & 0.99 & $0.99-1.00$ & 0.03 \\
\hline TBARS & 1.06 & $0.76-1.47$ & NS \\
\hline SOD & 0.93 & $0.66-1.30$ & NS \\
\hline TNF $\alpha$ & 0.47 & $0.28-0.80$ & 0.005 \\
\hline CRP & 0.74 & $1.14-1.30$ & NS \\
\hline IL-1 & 1.17 & $0.28-0.80$ & 0.005 \\
\hline
\end{tabular}

BMI: body mass index, GPx: Glutathion peroxidase, GRed: Glutathion reductase, TBARS: Thiobarbituric acid reactive substances, SOD: Superoxide dismutase, TNF- $\alpha$-tumor necrosis $\alpha$, CRP: C-reactive protein, IL-1: Interleukin. OR: odds ratio, CI: confidence interval, NS: not statistically significant.

\subsection{Correlations and Associations between EE and Different Variables}

Significant relationships were found between weight ( $\mathrm{P}<0.001)$, height $(\mathrm{P}<0.01)$, Albumin, GPx, IL-1, TNF $\alpha$ $(\mathrm{P}<0.05)$ and EE (Table 4). Multiple logistic regression analysis of EE (athletes and non athletes groups) and variables (sex, BMI, pubertal status, waist circumference, glucose, total cholesterol, TG, urea, uric acid, hemoglobin, total proteins, GPx, GRed, albumin, TBARS, SOD, TNF $\alpha$, CRP, IL-1) is shown in Table 5.

\section{Discussion}

The aim of this study was to evaluate nutritional status, oxidant/antioxidant and inflammatory markers, in athletes adolescents compared to non athletes.

Anthropometric parameters showed that athletes group had high weight and height compared to non athletes, whereas, there was no significant difference in BMI and WC in the both groups. These results were not in accordance with those found in young male handball players [8], and those in athletic adolescents [17], for weight and height, but the same results were noted for BMI.

In the current study, PA levels had no effect on serum concentrations of glucose, TC, urea, total proteins, and hemoglobin. However, vigorous PA reduced significantly serum TG in adolescents. Indeed, aerobic exercise decreased TG level in 18 years and older men [18].

During adolescence, adequate energy was required to meet both growth and development needs of the individual, as well as, the substrate demands associated with general physical activity, training and competition [19].

The present study showed that in athletes group, DEI was less than recommended intake of 9 to $12 \mathrm{MJ} /$ day [6]. These findings were also reported in female adolescents athletes, with low DEI compared to EE [20].

Otherwise, our athletes had a negative energy balance but their body weight was on average $6 \mathrm{~kg}$ heavier than that of non athletes, in spite of the same DEI but with a high proteins intake. Evidence points indicated that in a dietary energy restriction with a higher protein intake, in combination with a regular practice, resistance exercise can lead to gains in skeletal muscle mass [21].

The protein needs for the athletes are slightly higher than those for the general population [22]. In our study, total protein intake in athletes group was $1.64 \mathrm{~g} / \mathrm{kg} / \mathrm{day}$. This intake was explained by the high frequency of animal protein rich foods, such as meat, fish and eggs. A typical intake of protein for most athletes should be $1.2-2.0 \mathrm{~g} / \mathrm{kg}$ of body weight per day [23], which representing 10 to $30 \%$ of total energy intake for 4 - to 18 -years-old [24]. On the other hand, lipid intake in athletes adolescents (27\%) was less than that of non athletes group (29\%), and recommendations, knowing that adequate dietary fat is important to ensure an appropriate supply of fat soluble vitamins, and essential fatty acids, as well as, to provide adequate energy to support growth, and maturation of adolescent athlete [17]. Dietary surveys of adolescent athletes suggested that current dietary practices typically provide a fat intake of at least $30 \%$ of DEI $[25,26]$. 
In our study, athletes adolescents consumed $57 \%$ of carbohydrates (a mean of $6.23 \mathrm{~g} / \mathrm{kg} /$ day). This proportion was lower than that recommended for athletes under growing process and daily practice, to maximize muscular glycogen storage, carbohydrates should comprise $45 \%$ to $65 \%$ of total energy intake for 4- to 18-year-olds [27], in average of 6 to $10 \mathrm{~g} / \mathrm{kg} /$ day [28]. So, Anderson et al [29] suggested that although professional Soccer players readily achieve current guidelines for daily protein and fat intake, carbohydrates intake on the day before and in recovery from match play was not in accordance with guidelines to promote muscle glycogen storage.

More than $70 \%$ of our adolescents consumed breakfast every day, and 30\% occasionally, knowing that skipping breakfast has been associated with overweight [30].

Our results showed that non athletes group spent more time watching TV, than athletes group. A Brazilian study [31], in children and adolescents, reported that screen time was inversely related with PA. Similarly, Ferrari et al [32], found a higher prevalence of children meeting vigorous PA guidelines among children who watched $\leq 2 \mathrm{~h} /$ day television. There was no significant difference in total sleep between the both athletes and non athletes groups, suggesting that sleep time was not affected by the sport duration, in school or outside. These results were similar to those observed by Ribeyre et al [17], in athletic adolescents.

The regular exercise training is associated with numerous physiological adaptations of the body. One of the objectives of our study was to evaluate some oxidant-antioxidant and inflammation markers, in athletes compared to non athletes adolescents.

No significant difference was noted in TBARS concentrations, and GRed activity between the both groups. However, athletes group had higher SOD and GPX. Studies reported that these enzymes provide the primary defense against reactive oxygen species (ROS) generated during exercise, and their activities are known to increase, in response to exercise, in both animal and human studies $[33,34]$. Compared with non-athletes, higher SOD activity was noted in athletes, including handball players [8], karate athletes [35], footballers [36], and soccer players [37]. Indeed, high level of GPx, found in fit populations, and the positive relationship between GPx and fitness variables, support the paradigm that regular exercise upregulates the antioxidant defense, in response to the acute increase in ROS generation, during a single bout of exercise [38].

Our results showed no change in CRP and IL-1, whereas TNF- $\alpha$ concentration was significantly higher in athletes group. Said et al [39] have shown that circulating leukocyte, induced by maximum muscular exercise intensity, is superimposed a significant release of TNF- $\alpha$, in the blood compartment. However, Drenth et al [40] reported that the race endurance does not affect TNF- $\alpha$ concentration. The same authors have shown, few years after, that a run of $5 \mathrm{~km}$ is likely to decrease TNF- $\alpha$. Suzuki et al [41] have noted that TNF- $\alpha$ remained unchanged by a short-lived very intense muscular exercise, but increased significantly two hours later.

The multiple logistic regression analysis showed no significant association between sex, pubertal status, waist circumference, BMI, glucose, TG, total cholesterol, urea, uric acid, hemoglobin, total proteins, GRed, TBARS, SOD,
CRP and EE. However, GPx, albumin, TNF- $\alpha$, IL-1 showed a positive and significant association with $\mathrm{EE}$.

In summary, a negative energy balance due to inadequate DEI is observed in athletes adolescents. Slightly decrease of serum TG concentrations, and enhanced GPX and SOD activities are noted in athletes, compared with non athletes. However, significant associations are found between GPx, inflammatory markers and EE. Indeed, these results contribute to the recognition that adequate level of physical activity in adolescents leads to better health, while increasing PA should still be a public health priority. Longitudinal and intervention studies are warranted to give future recommendations.

\section{Statement of Competing Interests}

None.

\section{Abbreviations}

PA: Physical activity; DEI: Daily energy intake; EE: Energy expenditure; IPAQ-S: International Physical Activity Questionnaire-short form; MET: metabolic equivalent of task; BMI: Body mass index; BW: Body weight; WC: Waist circumference; SBP: Systolic blood pressure; DBP: Diastolic blood pressure; TG: triacylglycerol; SES: Socioeconomic status; OS: Oxidative stress; CRP: C-Reactive protein; TNF- $\alpha$ : Tumor necrosis factor- $\alpha$; IL-1: Interleukin-1; TBARS: Thiobarbituric acid reactive substances; SOD: Superoxide dismutase; GPx: Glutathione peroxidase; GRed: Glutathione Reductase; CI: Confidence Interval; OR: Odds Ratio. NS: not statistically significant.

\section{Acknowledgements}

This work was funded by the General Directory of Scientific Research and Technology Development (DGRS-DT) of the Ministry of High Education and Scientific Research.

The authors wish to thank the adolescents who participated in the study and all the health personal who aided to make it successful.

\section{References}

[1] World Health Organization (WHO). "Global recommendations on physical activity for health,” Geneva, Switzerland: WHO Press. ISBN: 978924159997 9, 2010.

[2] Ridley, K., Ainsworth, B.E. and Olds, T.S. "Development of a compendium of energy expenditures for youth," International Journal of Behavioral Nutrition and Physical Activity, 5, 45, 2008.

[3] Meskaite, A., Raistenskis, J., Stukas, R. and Kowalski, I.M. "Daily food intake in adolescents: Relation to parameters of physical fitness and weight status,” Polish Annals of Medicine, 20, 8-12, 2013.

[4] Gracia-Marco L, Valtue ña J, Ortega FB, Pérez-López, F.R., Vicente-Rodríguez, G., Breidenassel, C., Ferrari, M., Molnar, D., Widhalm, K., Henauw, S., Kafatos, A., Diaz, L.E., Gottrand, F., Maiani, G., Stehle, P., Castillo, M.J. , Moreno, L.A. and GonzálezGrosset, M. "Iron and vitamin status biomarkers and its association with physical fitness in adolescents: the HELENA study,” Journal of Applied Physiology, 113, 566-573, 2012. 
[5] Cárdenas-Cárdenas, L. M., Burguete-Garcia, A.I., Estrada-Velasco, B. I., López-Islasb, C., Peralta-Romeroc, J., Cruzc, M. and Galván-Portillo, M. "Leisure-time physical activity and cardiometabolic risk among children and adolescents," Journal of Pediatrics (Rio J), 42, 136-191, 2015.

[6] Purcell, L.K. "Sport nutrition for young athletes," Paediatrics and Child Health, 18(4), 200- 202, 2013.

[7] Montfort-Steiger, V. and Williams, C.A. "Carbohydrate intake considerations for young athletes," Journal of Sports Science \& Medicine, 6, 343-352, 2007.

[8] Djordjevic, D., Cubrilo, D., Macura, M,. Barudzic, N., Djuric, D. and Jakovljevic, V. "The influence of training status on oxidative stress in young male handball players," Molecular and Cellular Biochemistry, 351, 251-259, 2011.

[9] Cakir-Atabek, H., Demir, S., PinarbaŞili, R. D. and Gündüz N. "Effects of different resistance training intensity on indices of oxidative stress," Journal of Strength and Conditioning Research, 24, 2491-2497, 2010.

[10] Wärnberg, J., Nova, E., Romeo, J., Moreno, L. A., Sjöström, M. and Marcos, A. "Lifestyle related determinants of inflammation in adolescence,” British Journal of Nutrition, 98, S116-S120, 2007.

[11] Thomas, N. E. and Williams, D. R. "Inflammatory factors, physical activity, and physical fitness in young people," Scandinavian Journal of Medicine \& Science in Sports, 18, 543-556, 2008.

[12] Winkleby, M. A., Jatulis, D. E., Frank, E. and Fortmann, S.P. "Socioeconomic status and health: how education, income, and occupation contribute to risk factors for cardiovascular disease," American Journal of Public Health 82, 816-820, 1992.

[13] Craig, C.L., Marshall, A.L., Sjöström, M., Bauman, A.E., Booth, M.L., Ainsworth, B.E. and Oja, P. "International physical activity questionnaire: 12-country reliability and validity,” Medicine and Sciences in Sports and Exercise, 35, 1381-1395, 2003.

[14] Ainsworth, B.E., Haskell, W.L., Whitt, M.C., Irwin, M.L, Swartz, A.M, Strath, S.J. and Leon, A.S. "Compendium of physical activity: an update of activity codes and MET intensities," Medicine and Sciences in Sports and Exercise, 32, S498-S516, 2000.

[15] Musse, J.P., and Musse, N. GENI (Gestion d'Enquêtes Nutritionnelles Informatisées), version 6, micro 6, France, 2000.

[16] Quintanilha, A.T., Packer, L., Davies, J.M., Racanelli, T.L. and Davies, K.J. "Membrane effects of vitamin E deficiency bioenergetic and surface charge density studies of skeletal muscle and liver mitochondri,". Annals of the New York Academy of Sciences, 393, 32-47, 1982.

[17] Ribeyre, J., Fellmann, N., Vernet, J., Delaître, M., Chamoux, A., Coudert, J. and Vermorel, M. "Components and variations in daily energy expenditure of athletic and non athletic adolescents in free living conditions,” British Journal of Nutrition, 84, 531-539, 2000.

[18] Kelley, G.A. and Kelley, K.S. "Aerobic exercise and lipids and lipoproteins in men: a meta analysis of randomized controlled trials,” The Journal of Men's Health \& Gender, 3, 61-70, 2006.

[19] Aerenhouts, D., Deriemaeker, P., Hebbelinck, M. and Clarys, P. "Energy and macronutrient intake in adolescent sprint athletes: a follow-up study,” Journal of Sports Sciences, 29, 73-82, 2011.

[20] Hoogenboom, B.J., Morris, J., Morris, C. and Schaefer, K. "Nutritional knowledge and eating behaviors of female, collegiate swimmers," North American Journal of Sports Physical Therapy, 4, 139-148, 2009.

[21] Phillips, S.M.. "A Brief Review of Critical Processes in ExerciseInduced Muscular Hypertrophy,” Sports Medicine, 44, (Suppl 1):S71-S77, 2014

[22] Cotugna, N., Vickery, C.E. and McBee, S. "Sports Nutrition for Young Athletes,” Journal of School Nursing, 21, 323-328, 2005.

[23] Jenkins, D. and Reaburn P. "Guiding the Young Athlet," St Leonards, Australia: Allen \& Unwin, 146 -147, 2000.

[24] Otten, J. J., Hellwig, J.P. and Meyers, L. D, Dietary reference intakes: The essential guide to nutrient requirements, National Academies Press, Washington, 2006, 154.

[25] Croll, J.K., Neumark-Sztainer, D., Wall, M., Perry, C. and Harnack, L. "Adolescents involved in weight related and power team sports have better eating patterns and nutrient intakes than non-sport-involved adolescents," Journal of American Dietetic Association, 106, 709-717, 2006.

[26] Juzwiak, C.R., Amancio, O.M., Vitalle, M.S., Pinheiro, M.M. and Szejnfeld, V.L. "Body composition and nutritional profile of male adolescent tennis players," Journal of Sports Science, 26, 1209-1217, 2008.

[27] Hoch, A.Z., Goossen, K. and Kretschmer T. "Nutritional requirements of the child and teenage athlete," Physical Medicine and Rehabilitation Clinics of North America, 19, 373-398, 2008.

[28] Rodriquez, N.R., DiMarco, N.M. and Langley, S. "Position of the American dietetic association, dietitians of Canada \& the American college of sports medicine,” Journal of American Dietetic Association, 109, 509-527, 2009.

[29] Anderson, L., Orme, P. Naughton, R.J., Close, G.L., Milsom, J., Rydings, D., O’Boyle, A., Di Michele, R., Louis, J., Hambly, C., Roger Speakman, J., Morgans, R., Drust, B. and Morton, J.P "Energy Intake and Expenditure of Professional Soccer Players of the English Premier League: Evidence of Carbohydrate Periodization," International Journal of Sport Nutrition and Exercise Metabolism, 27, 228-238, 2017.

[30] Garcia-Continente, X., Allué, N., Pérez-Giménez, A., Ariza, C., Sánchez-Martínez, F., López, M.J. and Nebot, M. "Hábitos alimentarios, conductas sedentarias y sobrepeso y obesidad en adolescentes de Barcelona,” Anales de Pediatria (Barc), 83, 3-10, 2015.

[31] Dutra, G.F., Kaufmann, C.C., Pretto, A.D. and Albernaz, E.P. "Television viewing habits and their influence on physical activity and childhood overweight," Journal of Pediatrics, (Rio J) 91, 346-351, 2015.

[32] Ferrari, G.L., Araujo, T.L., Oliveira, L., Matsudo, M., Mire, E., Barreira, T.V., Tudor-Locke, C. and Katzmarzyk, P.T. "Association between television viewing and physical activity in 10-year old Brazilian children,” Journal of Physical Activity and Health, 12, 1401-1408, 2015.

[33] Sen, C.K. "Oxidants and Antioxidants in exercise," Journal of Applied Physiology, 79, 675-686, 1995.

[34] Ji, LL. "Exercise and oxidative stress: Role of cellular antioxidant systems,” Exercise and Sport Sciences Reviews, 135-166, 1995.

[35] Naghizadeh, H., Afzalpour, M.E. and Zarban, A. “The comparison of antioxidant status and lipid profile of karate athletes with non athletes," Journal of Birjand University of Medical Sciences, 16, 54-61, 2009.

[36] Metin, G., Atukeren, P., Alturfan, A.A., Gülyaşar, T., Kaya, M. and Gümüştaş, M. K. "Lipid peroxydation, erythrocyte, superoxyde dismutase activity and trace metals in young male footballers,” Younsei Medical Journal, 44, 979-986, 2003.

[37] Cazzola, R., Russo-Volpe, S., Cervato, G. and Cestaro, B. "Biochemical assessments of oxidative stress, erythrocyte membrane fluidity and antioxidant status in professional soccer players and sedentary controls,” European Journal of Clinical Investigation, 33(10): 924-930, 2003.

[38] Clarkson, P.M. and Thompson, H.S. "Antioxidants: what role do they play in physical activity and health?” American Journal of Clinical Nutrition, 72: S637- S646, 2000.

[39] Said, M., Feki, Y., Aouni, Z., Machghoul, S., Hamza, M. and Amri, M. "Effets des activités physiques intenses et soutenues sur les cellules immunitaires circulantes et la production des cytokines pro-inflammatoires chez des sujets entrainés et non entrainés," Sci Sports, 24, 229-237, 2009.

[40] Drenth, JP., Van Uum, SH., Van Deuren, M., Pesman, GJ., Van der Ven-Jongekrijg, J. and Van der Meer, J.W. "Endurance run increases circulating IL-6 and IL-1ra but downregulates in vivo TNF $\alpha$ and IL-1 $\beta$ production," Journal of Applied Physiology, 79, 1497-1503, 1995.

[41] Suzuki, K., Nakaji, S., Yamada, M., Totsuka, M., Sato, K. and Suqawara, K. "Systemic inflammatory response to exhaustive exercise," Cytokine kinetics. Exercise Immunology Review, 8, 6-48, 2002. 